Research Hospital, Italian Institute of Auxology, Milan, and Center for Sleep Disorders, Dept of Neurological Sciences, University of Bologna, Bologna, Italy.

\section{STATEMENT OF INTEREST}

None declared.

\section{REFERENCES}

1 Mediano O, Barceló A, de la Peña M, Gozal D, Agustí A, Barbé F. Daytime sleepiness and polysomnographic variables in sleep apnoea patients. Eur Respir J 2007; 30: 110-113.

2 Bahammam A. Excessive daytime sleepiness in patients with sleep-disordered breathing. Eur Respir J 2008; 31: 685-686.
3 Bahammam A, Syed S, Al-Mughairy A. Sleep-related breathing disorders in obese patients presenting with acute respiratory failure. Respir Med 2005; 99: 718-725.

4 Lombardi C, Parati G, Cortelli P, et al. Daytime sleepiness and neural cardiac modulation in sleep-related breathing disorders. J Sleep Res 2008; [Epub ahead of print PMID: 18503513]

5 Bonsignore MR, Parati G, Insalaco G, et al. Baroreflex control of heart rate during sleep in severe obstructive sleep apnoea: effects of acute CPAP. Eur Respir J 2006; 27: 128-135.

6 Heart rate variability. Standards of measurement, physiological interpretation, and clinical use. Task Force of the European Society of Cardiology and the North American Society of Pacing and Electrophysiology. Eur Heart J 1996; 17: 354-381.

DOI: $10.1183 / 09031936.00043308$

\title{
Lung volume measurements
}

\section{To the Editor:}

I read with interest the impressive paper by CAzzolA et al. [1] in a recent issue of the European Respiratory Journal.

However, I felt somewhat uneasy reading the recommendations on lung volume measurements, i.e. closing circuit dilution methods and body plethysmography.

CAzzola et al. [1] state "either method can be used... However they are not interchangeable, since moderate-to-severe airflow obstruction dilution methods tend to underestimate and body plethysmography tends to overestimate TLC".

Therefore, according to CAzzOLA et al. [1], in moderate-to-severe airflow obstruction no method is accurate. What, therefore, is the choice? To accept underestimation of lung volume since the dilution methods are "less expensive and less demanding"? Or, in spite of the overestimation of total lung capacity, to use a body plethysmograph, since it is "time saving"?

In fact, dilution methods do underestimate lung volume in moderate-to-severe airflow obstruction [2-4]. The more severe the airflow obstruction, the larger the underestimation [4].

Body plethysmography might indeed overestimate total lung capacity in airflow obstruction if incorrectly measured $[5,6]$. However, the plethysmographic method is accurate even in moderate and severe airflow obstruction by breathing or panting at $<1 \mathrm{~Hz}[7,8]$.

\section{Stanescu}

Medical School, Catholic University of Louvain, Brussels, Belgium.

\section{STATEMENT OF INTEREST}

None declared.

\section{REFERENCES}

1 Cazzola M, MacNee W, Martinez FJ, et al. Outcomes for COPD pharmacological trials: from lung function to biomarkers. Eur Respir J 2008; 31: 416-469.

2 Herzog H, Keller R, Amrein R, Matthys H, Joos J. Patterns of correlation of pulmonary function values determined by spirography and body plethysmography. In: DuBois $\mathrm{AB}$, Van de Woestijne KP, eds. Body Plethysmography. Basel, Karger, 1969; pp. 205-214.

3 Mikus JP, Robins AG, Burke GW, et al. Comparison of five methods for determination of FRC and TLC in 100 persons: appendix 6 of the American Thoracic Society Epidemiology Standardization Project. Am Rev Respir Dis 1978; 118: 92-104.

4 Rodenstein DO, Stănescu DC. Reassessment of lung volume measurement by helium dilution and by body plethysmography in chronic air-flow obstruction. Am Rev Respir Dis 1982; 126: 1040-1044.

5 Stănescu DC, Rodenstein DO, Cauberghs M, Van de Woestijne KP. Failure of body plethysmography in bronchial asthma. J Appl Physiol 1982; 52: 939-948.

6 Rodenstein DO, Stănescu DC, Francis C. Demonstration of failure of body plethysmography in airway obstruction. $J$ Appl Physiol 1982; 52: 949-954.

7 Shore SA, Huk O, Mannix S, Martin JG. Effect of panting frequency on the plethysmographic determination of thoracic gas volume in chronic obstructive pulmonary disease. Am Rev Respir Dis 1983; 128: 54-59.

8 Rodenstein DO, Stănescu DC. Frequency dependence of plethysmographic volume in healthy and asthmatic subjects. J Appl Physiol 1983; 54: 159-165. 